\title{
La violencia espacial
}

Escenario del teatro de Juan Mayorga

Refugio Chávez Ramírez

\section{OpenEdition}

\section{Journals}

Edición electrónica

URL: https://journals.openedition.org/cher/1754

DOI: $10.4000 /$ cher. 1754

ISSN: 2803-5992

Editor

Presses universitaires de Strasbourg

\section{Edición impresa}

Fecha de publicación: 1 diciembre 2017

Paginación: 135-151

ISBN: 978-2-86820-962-7

ISSN: 1968-035X

\section{Referencia electrónica}

Refugio Chávez Ramírez, «La violencia espacial», reCHERches [En línea], 19 | 2017, Publicado el 01 diciembre 2021, consultado el 08 febrero 2022. URL: http://journals.openedition.org/cher/1754 ; DOI: https://doi.org/10.4000/cher.1754

\section{(c) $)(1)(2)$}

Ce(tte) œuvre est mise à disposition selon les termes de la Licence Creative Commons Attribution Pas d'Utilisation Commerciale - Partage dans les Mêmes Conditions 4.0 International. 


\title{
La violencia espacial Escenario del teatro de Juan Mayorga
}

\author{
Refuglo Chávez Ramírez ${ }^{1}$
}

\begin{abstract}
- Dor qué discutir el teatro desde la política (y lo político)? ¿Por qué no? 2 El teatro surge del acontecer social. Y, como (casi) toda manifestación artística, es una expresión simbólica de reclamos políticos, evidentes o no. El teatro es pues una manifestación política, y, en tanto lenguaje, materializa experiencias y evidencia concepciones frente y sobre el mundo (Arrieche, 2012). Como lo afirma Dubatti (2007: 162): «el teatro instala un campo de verdades subjetivas, cuya intelección permite conocer a los sujetos que las producen, portan y trasmiten, encierra formas subjetivas de comprender y habitar el mundo». Una pieza teatral es una práctica política, testimonio del arte y la política, de todo aquello que puede suceder al seno de una sociedad, como la violencia. La violencia política y la política de la violencia son objeto de discusión en este texto, en particular las formas en las que dichas violencias se repiten a lo largo del planeta (lo que puede denominarse «democratización de la violencia»). La violencia, consideramos, implica la acción lesiva de un individuo sobre otros. El uso de la fuerza (física, verbal, simbólica) en conductas o situaciones que provocan, o amenazan, un sometimiento (físico, sexual o psicológico) al individuo (incluido el yo) o a la colectividad (Blanco 2001: 10), o limitan sus potencialidades presentes o futuras (Galtung 1995).

Por ejemplo, desde fines del siglo pasado y en lo que va del presente, podemos pensar que las situaciones violentas utilizan ciertos modelos y medios de una manera más común ${ }^{2}$. Tras dichos modelos, se esconde siempre el
\end{abstract}

1 Doctor en gobierno y administración pública por la Universidad Complutense de Madrid y el Instituto Universitario de Investigación Ortega y Gasset. Actualmente es lector de español en la Universidad de Estrasburgo y es miembro del equipo de investigación CHER en la misma universidad.

2 Aquí cabe mencionar la muerte «sanitaria» o tecnificada -drones-, la espectacularización de la muerte e incluso su difusión audiovisual en tiempo real. 
argumento de un objetivo o fundamento moral, la lucha, el conflicto, la opresión y posterior violencia se derivan de una visión que logra imponerse sobre otra. Lo sorprendente es que avanzado el tiempo, la violencia sigue siendo cotidiana para muchos habitantes, sea por medios tradicionales (asesinatos, robos, violencia de género, violencia estatal, etc.), o por medios creados en la nuevas condiciones neoliberales ${ }^{3}$.

La violencia, consideramos, se dispersa cada vez más y rompe las estratificaciones sociales, la sociedad interioriza y reproduce los comportamientos violentos, en ocasiones creando nuevos. Este contexto conforma el escenario espacial del que se nutre la obra de Mayorga, de ahí que nuestro objetivo sea mostrar una rápida descripción de los factores que han propiciado o favorecido que la violencia sea el nuevo ocupante político del espacio.

\section{La violencia como base fundacional del Estado de derecho}

La llegada de la modernidad trae consigo la creación del Estado-nación (base legal y de gobierno para una población dentro de límites territoriales), esta institución se encargará de regular y de crear/eliminar las relaciones sociales de comunicación y determinación a fin de mantener el orden social, garantizar la educación y la salud y unificar la cultura (Sermeño 2000: 296-297). La posterior aparición de un sistema de leyes e instituciones dará origen al Estado de derecho, con lo cual, el derecho deviene principal instrumento de gobierno (base y límite de acción), guiando, además, la conducta humana y demandando que los poderes de las instituciones lo interpreten y apliquen congruentemente (Raz 1985). Este aspecto es muy importante porque violencia y derecho corren paralelos.

Para Benjamin, la violencia se une al derecho en dos variantes. En la primera la violencia es, como medio, poder que funda o conserva el derecho. La segunda es una forma mítica, simple manifestación de los dioses, de su voluntad y, sobre todo, de su ser (Benjamin 1998: 32). Agamben considera que ésta se aplica directamente desde un Estado soberano sobre la vida biológica, aísla al ser humano de lo que hay de corporal, le despoja de su vida política y se convierte en lugar de excepción, de imposición violenta de los vínculos políticos (Serratore 2010). Para Derrida, la violencia es antecedente de todo derecho. Hacer la ley supone una violencia que no es justa o injusta en sí misma: hay una violencia neutra o espectral detrás de todo acto jurídico, la justicia es un suceso no violento que, sin embargo, no puede borrar la violencia originaria (Pereyra 2011: 34). Así, vemos en estas posturas que las instituciones de la modernidad se originan en la violencia (vía el derecho que marca y ordena los espacios público y privado), permitiéndole a ésta permanecer en los entramados jurídicos contemporáneos, y a éstos, al ser aplicables en un territorio, obligar a

3 Como el bullying, reflejo de la violencia estructural de la sociedad, aterrizado sobre un grupo de la población particular: los adolescentes -nuevo segmento de la población creado a la llegada de la modernidad tardía-. 
los sujetos dentro de él a ser persuadidos por la norma o coercionados por una sanción ${ }^{4}$. Evidentemente, dicha violencia es la base fundacional del Estado, y, aunque vinculada, está fuera del foco creador de la violencia generada al interior de las democracias. Es decir, la violencia que funda el Estado de derecho no es la causante de aquella que se origina en los estados dictatoriales, por ejemplo, ni la violencia policial de muchos países occidentales es consecuencia de aquellos fenómenos que han dado fundación al Estado moderno, el desarrollo de estos nuevos tipos de violencia son originados, más bien, en una base neoliberal que opera reconstituyendo completamente las estructuras de interacción social.

\section{El liberalismo, diseminador del germen de la violencia}

El liberalismo aparece en el siglo xvin y permite la entrada de la economía en el Estado, marcando un cambio profundo en la forma en la que éste se organiza. El liberalismo busca permitir el «desarrollo natural» de la economía de mercado a través de la libertad e igualdad, desde las que se desarrollan herramientas, materializables en las instituciones, aplicables para asegurar su propia reproducción. Dos de ellas destacan: a) la sustitución del factor subjetivo (trabajador) por el objetivo (medio de producción), desvalorizando lo vivo frente a lo no vivo, constituyendo un detrimento creciente de la vida y una deshumanización del trabajador (Marcuse 1993: 303); y, b) la imposición «dentro de cada empresa de un sistema anárquico de concurrencia que engendra el despilfarro más desenfrenado de medios sociales de producción y fuerza de trabajo, obligando además a sostener un sinnúmero de funciones inexcusables, perfectamente superfluas» (Marx 1978: 443). Para Marx, la diferencia específica entre los individuos (sujetos que intercambian) se borra sistemáticamente en la esfera de la circulación (base del modo de producción capitalista); estos aparecen en una relación de total igualdad entre sí (indiferenciables) y libertad (sin ella no puede existir el libre intercambio). Este sistema comercial avanza hasta los albores del siglo xxI, con nuevos procesos de manufactura, a una forma industrial orientada a la producción y al ensanchamiento y expansión del mercado para satisfacer las demandas de centros urbanos cada vez más grandes, originando los modelos fordistas de producción en masa.

4 El derecho vive con la paradoja de controlar la violencia legitimándola y reproduciéndola. Esta paradoja, según Rivera (2003), se nutre de tres realidades básicas: 1) la violencia se encuentra en el origen de muchos ordenamientos jurídicos modernos (revoluciones, rebeliones, guerras civiles, ocupaciones militares, imposiciones, etc.) y en muchos casos la convierten en motivo de gloria para la experiencia comunitaria; 2) las sociedades modernas necesitan disciplinar la violencia para mantener el orden (no eliminarla totalmente, sino someterla a la racionalidad de quienes están al mando y dictaminan quién puede usarla, cuándo, cómo y por qué motivos); y 3 ) el derecho depende parcialmente de la violencia para lograr su eficacia, es decir, no puede eliminarla en su totalidad, pero tampoco depender estrictamente de la persuasión. 
Con la llegada del liberalismo el Estado pierde, paulatinamente, sus capacidades e instituciones (mismas que garantizaban derechos ciudadanos), haciéndolo incapaz de fijar los términos y límites del actuar de entes económicos sobre los individuos, sobre su cuerpo mismo, pues éste es la base originaria de la riqueza y de toda política monetaria. Como dice Napoli (2014), «la primacía de la economía en la política supuso una relación social violenta donde todo individuo que no se discipline o someta es sujeto de una violencia física mayor y más directa (desde infracciones económicas y cárcel, hasta ataques directos que atentan contra su integridad o causan su muerte)».

También trajo consigo una serie de transformaciones socioculturales (la masificación de la cultura). El progreso tecnológico abarató la producción de infraestructuras (casas, edificios y obras viales que se producían de igual manera) pero también de servicios culturales (prensa, música y medios como las películas y la televisión), permitiendo el desarrollo de una cultura para las masas, usada como forma de control: al ser impuesta desde arriba hace pasiva a su audiencia, limita su elección entre consumir o no ${ }^{5}$. Una de las implicaciones fue la atomización de las sociedades, el aislamiento y la eventual caída en el dinamismo social (Núñez 1978: 26) ${ }^{6}$. El individuo es sustituido por la masa, conjunto amorfo de personas, donde cada ser humano se integra indiferente y despersonalizadamente ${ }^{7}$ (Álvarez 2013: 64).

\section{Democracia y violencia}

En estas condiciones, el modelo organizador de la sociedad (democracia) ya no implicaría la negociación de los individuos/actores, sino el ejercicio del poder y la violencia. En teoría, la democracia permitiría a los actores de un territorio la negociación, propuesta y realización efectiva de sus demandas y derechos (generación de ciudadanía) (OAS y PNUD 2010). Sin embargo, ésta:

- Reposa sobre el principio de desigualdad (económico-política): un gran porcentaje de la población se encuentra en franca desventaja respecto a un grupo particular (a nivel global, el $45 \%$ de la riqueza, y la consecuente toma de decisiones, se concentraba en $0.7 \%$ de la población global (El País 2015)).

- Es capaz de definir la violencia: según Dumouchel (2012: 119), las democracias pueden distinguir entre violencia política y el resto de la

5 Desde luego que, frente a este escenario, aparecieron las contraculturas en distintas disciplinas, sin embargo, dado el limitado alcance, no pueden aquí ser comparadas con el alcance de dichos progresos tecnológicos.

6 Klossowski (1972) considera que ello provocó que tanto la conciencia crítica y reflexiva como la posibilidad de rebelión fueran severamente limitadas.

7 Dos características suyas lo corroboran: la uniformidad (que alude a una igualación en el sentido de la «necesidad de ser igual a los demás», de pertenecer a un grupo) y el anonimato (vinculado a la despersonalización, y conformado en un escenario donde nadie se conoce y en que el individuo desee perderse). 
violencia. La primera deviene legítima por haber ocurrido. Un acto violento es político si gana legitimidad (por ejemplo, un ataque con drones en Medio Oriente que causa pérdidas humanas civiles gana legitimidad ante la población porque así lo decide un gobierno). Y la legitimidad, que hace la diferencia entre violencia «buena» (legítima y justificada) y «mala» $\left(\right.$ crimen $^{8}$ ), se otorga por un Estado (o un actor con mucho poder sobre determinado territorio y su(s) comunidad(es) política(s)) que ostenta el monopolio de la violencia legítima. Mantener dicho monopolio necesita que se dicte a todos la diferencia entre la violencia buena de la que no lo es (legitimándola). La violencia política libera a los agentes de su propia violencia sin tener que cometer ningún acto de violencia. Cuando una persona asimila el discurso sobre el terrorismo o sobre la xenofobia, la violencia cesa de ser percibida como tal, se convierte en legítima a los ojos de $\operatorname{todos}^{9}$ (ibídem).

Por ello, una de las formas que tiene el sector poblacional vulnerado/ vulnerable de hacerse visible/visibilizar es la violencia. Así, se enfrenta lo que denominamos (Chávez y De la Cueva 2015) como «democratización de la violencia»: uso de ésta por cualquier actor (sociedad civil, el Estado y su cuerpo de instituciones, actores económicos privados, sindicatos, etc.), pero no necesariamente todos, para acceder a la política institucional, modificar el orden actual y utilizar el poder a su favor. Por medio de acciones o manifestaciones físicas y simbólicas con las que se atenta contra objetos físicos (individuos, instituciones, infraestructuras o instituciones) e inmateriales (el contenido de las constituciones, el diseño de las instituciones, las formas de acción de los cuerpos de control estatal, las políticas públicas, las acciones sociales). No es que la violencia devenga regla o ley general, sino que toma lugar una acción conjunta, resultado y creadora de las alianzas entre actores en la búsqueda de sus objetivos (Kalivas 2003: 487). Es un fenómeno que opera en diferentes campos (ideas, comportamientos y relaciones $)^{10}$, que actúa como causa/efecto, que se modifica y

8 Cada régimen político (democrático o no) tiende a etiquetar a algunos de sus oponentes como criminales (ya sea el terrorismo islámico para las democracias occidentales, los activistas ambientales en México, las autodefensas en territorios en conflicto, etc.) más que ser considerados como oponentes políticos legítimos. Esto no se encuentra vinculado, de ninguna manera, a la homogeneización de los actos de cada actor, sencillamente nos remite al poder de las democracias para asignar legitimidad a sus actos y decisiones.

9 Desde luego que la postura de la víctima no reconoce la violencia como legítima, en este sentido, quien tiene el monopolio perseguirá dos estrategias: intentar que la víctima (o el resto de su clase) esté de acuerdo con la violencia que sufre (que la legitime) y exportar la violencia del Estado fuera de su dominio donde se define el monopolio (guerras de conquista y colonizaciones) (Dumouchel 2012: 123).

10 Ideas: los individuos generalmente adquieren creencias, conceptos, reglas, metas y valores de sus ambientes, estos dan forma a sus propios impulsos ( $\mathrm{y}$ a los mutuos). Comportamientos: en ellos se canaliza la autonomía de los motivos, impulsos y oportunidades; $\mathrm{y}$, Relaciones: transacciones que involucran cierto grado de negociación 
es modificado por los vínculos sociales, las estructuras y los procesos. En síntesis: la violencia conforma un escenario espacial ceteris paribus donde los actores se desenvuelven y procuran manifestarse políticamente para alcanzar sus objetivos.

\section{El espacio en el contexto actual}

Desde hace poco más de un siglo se han derrocado paulatinamente las barreras espaciales que limitan la producción de riqueza y la acumulación de capital, mediante innovaciones tecnológicas en comunicaciones (ferrocarril, telégrafo, radio, automóvil, etc.), producción, comercialización e intercambio de bienes y servicios, generando la impresión de que el capital se puede reproducir en ausencia de su relación con el espacio. Eventualmente, se ha logrado implantar en la mentalidad social la idea del espacio como mero contenedor inerte, aislado sin relación con el tiempo y los fenómenos sociales ${ }^{11}$. Las prácticas culturales, económicas, ecológicas y sociales de esta visión ayudaron a excluir las raíces territoriales y a suprimir el movimiento de los individuos, conminándolos a ser sólo ecos de las reivindicaciones económicas ${ }^{12}$ (Beltrán 2013).

Sin embargo, el espacio nunca desapareció, ni perdió su importancia y complejidad. Por el contrario, encierra en sí las vivencias individuales, cobra vida propia al interactuar con un individuo, puede limitarle o condicionar su comportamiento. Es un espacio ontológico que define la cotidianeidad, al ser conocimiento, discursos, regulaciones, actuaciones y representaciones, y ninguna forma de producción puede abolir un lugar dado que las vivencias son personales, diferentes, un espacio es un fractal.

A lo que asistimos, es más bien a una reproducción del espacio, resultado de una lucha política. La mercantilización de los sectores públicos ${ }^{13}$ ha hecho que el

y creatividad entre personas y grupos (más allá de ideas y comportamientos) por medio de las cuales los humanos desarrollan sus personalidades y prácticas (Tilly 2003: 5).

11 La liberalización económica no abolió el espacio de nuestras vidas, sino el interés hacia él. Bauman (2009) considera que actualmente vivimos un estado de revolución permanente que no permite anticipar el futuro (el otro absoluto), planificar o hacer análisis sobre el presente, propiciando que los mecanismos sociales sean insuficientes para describir los espacios (sus características y composición), deviniendo entonces indefinibles.

12 Las ciencias sociales (y las humanidades) han estado influenciadas por esta visión y han reducido el análisis del espacio a una descripción física, olvidando el papel de las relaciones e interacciones individuales/comunitarias humanas en la construcción de un mismo espacio. El acercamiento predominante es una división radical entre la realidad física que desarrollan los cuerpos en el espacio y su medición en el intervalo de tiempo en que los fenómenos o las interacciones entre los cuerpos ocurren (Beltrán 2013:140).

13 Transformación radical, dice Harvey (2004), posible por el proceso de financiarización (la expansión masiva de instrumentos y mecanismos financieros especulativos), en especial, la gestión y manipulación de la crisis (como el uso de la deuda para despojar 
Estado de bienestar diese un vuelco hacia su militarización y el control social: si antes la producción industrial absorbía el excedente demográfico, ahora se aísla y neutraliza (de ahí el auge de las prisiones) para evitar los levantamientos y las rebeliones, razón que explica el ensañamiento de la justicia contra los pobres (que, fuera del estado de bienestar europeo, desconocen las ayudas sociales). Los Estados, ocupados por lógicas neoliberales, manipulan el espacio en formas novedosas como la guetización de las comunidades (comunidades cerradas o aisladas del resto de la estructura urbana), la vigilancia electrónica de las plazas públicas, las campañas de miedo destinadas a atemorizar/seducir poblaciones (Fox News, como ejemplo de una campaña de miedo permanente), etc. Espacios como las urbanizaciones son cada vez más cerrados hacia afuera (controles migratorios) y dentro de sí mismos (fronteras móviles: policías y sistemas de vigilancia), creando extraños en el plano interno y el externo. Son industrias masivas de extraños. En el capitalismo, el extrañamiento es patrón normal y cuasi-universal de las relaciones humanas (Iborra y Tosarelli 2014: 5).

Para el poder neoliberal no existe el espacio porque es capaz de fluir, de desprenderse de todos los aspectos de las relaciones humanas. El impacto que ello tiene, refiere Castells (1995), es una creciente igualación comercial de los espacios habitados en el globo (franquicias y demás), fomentando la homogeneización cultural y vital (lo que Ritzer (1996: 167) denomina macdonalización), dando forma a nuestra concepción de las relaciones sociales y la ocupación de los lugares ${ }^{14}$. Estos espacios, dice Augé (2000: 84), son «no-lugares», porque no son en sí mismos lugares antropológicos ni integran los lugares anteriores, sólo expresan el individualismo, la precariedad, lo provisional y lo efímero. Resumiendo, esta supuesta «desaparición» del espacio no es más que la nueva forma de control del yo en una etapa de acumulación por desposesión (privatización de los bienes comunes); la personificación de un régimen político violento. Analizaremos la violencia a través del espacio en las sociedades contemporáneas, y desde ahí revisitaremos la obra de Mayorga.

de su riqueza a las economías vulnerables y enviarla a los más poderosos). Con este, se invierte en la economía especulativa (divisas, deudas, acciones), no en la producción, desplazando el trabajo por el capital, desinvirtiendo en los barrios urbanos, regiones, naciones y continentes enteros, precarizando el empleo, destruyendo el medio ambiente, generando disturbios y eventuales conflictos armados. Este sistema ha creado un "excedente» masivo de población: desempleados, marginados, pobres y desposeídos (proletariado paria, según Davis (2004)). Los Estados responden a este «exceso» con más exclusión, criminalización y políticas anti-inmigrantes, a menudo con el apoyo de fuerzas privadas.

14 Debord (2009: 77) afirmó que cuanto más un lugar se deja a la libertad de juego, más influye en el comportamiento y más grande es su fuerza de atracción (por ejemplo, Mónaco o Las Vegas). 


\section{El espacio y la violencia}

Los espacios (construidos o imaginados) son uno de los elementos más estables de la vida cotidiana, pues no sólo conforman un fondo inerte o neutral, sino que influyen en los patrones y formas de convivencia social, son relevantes para la producción y la construcción de comportamientos. Éstos, sostiene Foucault (1979: 148), "proporcionan posiciones fijas y permiten la circulación; forjan segmentos individuales y establecen vínculos operativos; marcan lugares e indican valores; garantizan la obediencia de los individuos, y también una mejor economía de tiempo y el gesto».

Frente a la crítica de la pasividad social de esta perspectiva (los individuos son entes pasivos, los espacios actúan sobre ellos pero no a la inversa), De Certeau (1984: 117) propone distinguir entre «lugar» y «espacio». Un lugar es un espacio construido, estable como todas las formas físicas, mientras que un espacio es un lugar practicado ${ }^{15}$. En este sentido, son los espacios, no los lugares, los que pueden llegar a afectar las interacciones sociales y generar conflictos (especialmente si implican la asignación de los escasos recursos o la visualización de determinados tipos de status social). Un cierto grado de violencia siempre ha estado conectado a imperativos territoriales que implican la definición y defensa del espacio, así como las nociones de pertenencia y exclusión. La violencia puede asociarse a un territorio y ganar legitimidad en él (Wood 2007: 34). Esto es lo que se denomina como producción y construcción de violencia asociada al espacio.

El primer proceso se refiere a la aparición de manifestaciones rituales dentro de un espacio, significando con ello el control del mismo, o el uso de la fuerza para excluir/expulsar físicamente (establecimiento de la dicotomía: «nosotros» y «ellos»). Algunos espacios proporcionan contextos para mantener ciertas relaciones sociales (jerarquías o nociones de pertenencia), otros remarcan el papel de las élites sociales y su papel de vigilantes en las fronteras que ellos mismos crean (Wood 2007: 25).

El espacio también «construye» la violencia, es decir, crea las formas en que los actos son interpretados. La narrativa que no sólo describe un suceso en sí, lo explica con interpretaciones de la experiencia cotidiana. Por ejemplo, determinados espacios son asociados al peligro y/o violencia según los imaginarios sociales (noticiarios) y según instrumentos formales (como los informes policiales) (Wood 2007: 29).

15 Por ejemplo: si una calle es definida geométricamente en la planificación urbana es un lugar, y deviene espacio con los transeúntes que la recorren y habitan. La lectura es un espacio producido por la práctica de un texto escrito (lugar constituido por un sistema de signos). 


\section{Violencia y espacio en la obra de Mayorga}

El teatro no puede dejar de establecer un diálogo con la realidad histórica de la que forma parte. Al tratar sobre la experiencia humana incluye lo moral, lo histórico, lo político, lo social, lo antropológico (si no asume esta condición atenta contra su propia naturaleza ${ }^{16}$ ). Así, toda pieza expresa, parcial o totalmente, un momento histórico, vía un diálogo (que no busca relatarla explícitamente pues no es espejo de la realidad, al hacerlo deviene periodismo) que enriquece, multiplica y hace más complejos los vínculos (Levy-Daniel 2009). Aquí nos interesa discutir la representación teatral de la violencia y su vinculación con el espacio, estructura histórica de la experiencia que hace del teatro una convención cultural (Cruciani 2010) y permite establecer un campo delimitado para la significación, pues si el territorio es el dominio de los objetos y de las acciones, el espacio del teatro es el dominio de los significantes (Urrutia 2004: 43).

La violencia, decíamos en la introducción, amenaza y o condiciona el actual presente y futuro de un individuo, por lo que puede ser cubierta en el teatro de maneras múltiples. En el caso de Mayorga, se trata de simples alusiones: todo atentado físico es casi siempre encubierto por metonimias. Su objetivo no es mostrar explícitamente la violencia (al menos no en todas sus piezas), sino recuperar la vivencia de ésta en el cuerpo o cuerpos de los personajes. Así, la localiza, no en el plano personal, sino en el espacio donde los personajes se encuentran, creando situaciones donde la coacción no predomina. La característica distintiva de su teatro es, parafraseando a Blair (2005) «que enuncia la producción de la violencia, la revela sin introducirla, la evidencia como proceso mediador que interconecta información, personas y espacios sin ser totalitaria». Al leer el conjunto de obras podemos encontrar un entramado en donde la violencia reposa sobre (y acompaña) representaciones mentales (imaginarios, significaciones, tramas discursivas, aspectos que alimentan las relaciones sociales y las resignifican). Se trata de la dimensión objetiva que nota Zizek (2008). Es decir, la violencia es co-creada con el receptor de su obra (lector/espectador), quien debe reconstruir lo aludido desde la experiencia y memoria personal / colectiva que habita en él.

Siguiendo a Lambert (2015), si consideramos que el cuerpo se detiene en la piel concluiríamos que no existe una violencia «subjetiva» (explícita, física) en el teatro de Mayorga. Si extendemos los límites del cuerpo a la existencia de ciertos elementos externos (agua, oxígeno y el entorno de manera muy general), y su

16 No porque el teatro refleje un momento histórico-político tiene que obligar al espectador a tomar una posición determinada y/o movilizarse hacia cierto objetivo -aquel que debe ser transmitido al público para conseguir el efecto buscado-, de hacerlo, perdería la pluralidad de sentidos posibles en favor de un sentido único. Su razón de ser no es sólo didáctica, de ahí que obras como las de Mayorga tengan un carácter eminentemente político sin que llegue a dictar al lector/espectador cuáles son las metas legítimas a perseguir y cuáles los medios para alcanzarlas. 
privación o alteración afecta severamente nuestras funciones vitales ${ }^{17}$, entonces podríamos ver que lo que se afecta en muchas de sus obras no es precisamente el cuerpo mismo, sino lo que el autor denomina como "atmósfera», colocando a la violencia en un plano «objetivo», donde el espacio es imprescindible, tanto en diseño como en efectuación. Tendríamos entonces que el espacio es tan importante que llega a veces a convertirse propiamente en personaje de su teatro. Es por ello que este análisis se centra en el tratamiento del espacio de sus obras escritas, (consideramos) elemento potenciador de la violencia.

\section{La configuración del espacio en las piezas de Mayorga}

Dada la relación de causa-efecto entre política y espacio (proyección de la sociedad que lo habita (Lefebvre 2013) ${ }^{18}$ ), más que dominio de la realidad, el espacio es un montaje de orden político (Latour 2004). Este argumento agota la dicotomía entre naturaleza y sociedad constituyendo una comunidad donde coexisten humanos y no humanos ${ }^{19}$. Así, la acción política de un espacio lo vincula directamente al régimen en el que opera, pero también le otorga independencia de las circunstancias que permiten y producen las relaciones de poder, afectando a los actores en su interior. Éste es el tipo de espacios que encontramos en la obra del autor. En sus obras, la configuración espacial es el escenario de crisis: crea situaciones que infunden en los individuos ciertos elementos compositivos que llegarían a condicionar, no sólo su movimiento, sino su devenir. El espacio es pues, signo y significante de los valores sociales (de la sociedad y sus instituciones), crea y determina el comportamiento, acción, palabra y sonido de los individuos.

La disposición del espacio no es casual. Al predisponer las relaciones, la comunicación, la interacción con el/lo otro, puede condicionar y determinar el comportamiento de los personajes ${ }^{20}$. En ciertas piezas de Mayorga el espacio puede ser abierto o cerrado ${ }^{21}$ :

17 Ejemplos de esto son las cámaras de gas de los nazis, pero también los métodos de tortura usados en la actualidad, como el confinamiento en cajas tan reducidas que imposibilitan la respiración, o el ahogamiento controlado.

18 El espacio es una relación social vinculada a las relaciones de propiedad (de la tierra) y vinculada a las fuerzas productivas en esa tierra. Es «producto que se consume y medio de producción: redes de cambio, flujos de materias primas y de energías que configuran el espacio y que son determinados por él» (Lefebvre 2013: 141).

19 Simondon, Deleuze y Whitehead afirman que los objetos llegan a existir y perduran en el tiempo (Shaviro 2011).

20 Parafraseando a Pallasmaa (2006: 41), el individuo enfrenta al espacio con su cuerpo, su mirada le proyecta sobre las superficies donde se encuentra, siente el tamaño del espacio. El cuerpo siente el espacio y se define.

21 También puede ser permeable (flexible al cambio, permite la circulación sin romper su función); los contrastes suelen ser más evidentes. 
- Los espacios abiertos de sus obras rompen sus propios límites, devienen metafísicos, borran los límites de la imaginación de los personajes. Esta apertura alimenta el conflicto (Hamelin, Himmelweg, La Tortuga de Darwin, Reikiavik).

- En otras, el espacio es cerrado, reducido, claustrofóbico, aunque su propósito es similar: dilatar la violencia al interior de los personajes, de sus discursos y acciones, a fin de asegurar la visibilidad y movimiento de estos y evitar que sean engullidos (El gordo y el flaco, Palabra de perro, Últimas palabras de copito de nieve, La paz perpetua, El arte de la entrevista, Famélica). Estos espacios evidencian dominación, pues su reducción implica cierta imposibilidad de escape.

Ambos parecen conformar la atmósfera sicológica y espiritual que envuelve a los personajes, y desarrollar los conflictos de la obra. El espacio se vuelca sobre los sentimientos humanos, torna hostil el ambiente, opresivo. En ambos formatos los personajes son individuos exiliados, imposibilitados de transformación por contextos. Tanto espacios abiertos como cerrados son creaciones de un contexto mayor que limita y condiciona al individuo.

El espacio marca el ritmo de movimiento en piezas como Hamelin, en cuya ciudad existe un adentro (espacio civilizado) y un afuera (resto de la ciudad). El espacio separa a quienes pueden moverse libremente (Montero y Rivas) de quienes no (Josemari), limitándolos. La ciudad de la pieza está bifurcada. Hay una parte donde existe una densidad confusa de construcciones precarias, molesta y de difícil acceso, visualmente inconexo, un afuera penetrado por el salvajismo. Por el otro, una ciudad ordenada donde las cosas funcionan, desde ésta emana una violencia (reflejada en la justicia) que parece buscar purificar su otra mitad para incorporarla a sí misma, a la civilización. En la pieza los personajes se conforman desde el espacio, entran en diálogo con él desde sus potencialidades sensibles, afectivas, perceptivas, intelectuales, motrices. El espacio dialoga con la(s) subjetividad(es).

Otro ejemplo: el campo de concentración en Himmelweg tiene una función práctica (en este caso, el espacio es un cúmulo de funciones simbólicas), es un escenario que oculta los «hombres flacos con pijamas de rayas, los hornos, el humo, la ceniza» (Mayorga 2011: 148), un montaje teatral. Esta función social del espacio teatral determinará la relación entre actores y espectador (ambos personajes del texto), desde ella se desencadenará el eje dialéctico de la obra.

Decíamos que el espacio puede devenir personaje independiente. Cuando eso sucede interactúa, e incluso se fusiona, con suceso(s ${ }^{22}$ o con el tiempo (Tshumi 2015). Por ejemplo, la combinación entre espacio y suceso es evidente si observamos las nuevas tecnologías de comunicación. En la pieza El arte de

22 Tschumi (2015) ilustra cómo es indisociable lo que sucede en medios electrónicos de lo que sucede en el espacio real, creando una nueva forma de mediación entre medios y nuestras interacciones con los espacios (un ejemplo reciente es lo que sucedió en las plazas del Tahir y Sol, donde protesta real y virtual parecían fundirse). 
la entrevista, el diálogo se establece de manera intermitente entre personajes y cámara, es decir, alternándose (personaje-cámara-personaje) de una forma ininterrumpida, convirtiendo al medio, objeto en un personaje más. La fusión de espacio y tiempo se coagula en algunos casos en la memoria de los personajes, pasado y presente dialogan conjuntamente. La pieza se conforma a través de circuitos temporales que actúan sobre la comunicación y acción de los personajes. La ciudad de Varsovia (en El Cartógrafo ${ }^{23}$ ) sobre la que camina Blanca es y no la misma que ha observado en las fotos de una exposición. La búsqueda en el mismo espacio de un pasado en el presente conforma este mosaico.

En ambos, el espacio es potenciador, incide directamente sobre los personajes, desencadena la acción en ellos. Su diseño (arreglo) es herramienta clave para entender la violencia objetiva (aquella que hace que los cuerpos se adapten a las condiciones que el espacio les propone, transformando su realidad mediante la acción). La violencia se revela junto a la organización espacial, anticipa los comportamientos corporales. Por ejemplo, en Himmelweg, la estación de trenes supone la posibilidad de un desplazamiento masivo de los habitantes del campamento a un campo de concentración. De manera que la existencia de la estación y del tren no supone una protección (vía el escape) sino que los conmina a actuar para sobrevivir, estos crean condiciones de sujeción dentro y fuera del campamento: dentro se es prisionero del exterior, fuera se es prisionero del cuerpo. En ambos casos, se expropia al individuo en su totalidad.

Una segunda distinción de la violencia en las obras del autor concierne al espacio como lugar de desarrollo de conflicto. En este caso, la idea de un sujeto de derecho es refutada al descubrir la falibilidad de la capacidad del individuo para autorrealizarse. Es decir, objetos y espacios condicionan el desarrollo del personaje, pues están vinculados a determinada intensidad política y violencia. En Palabra de perro asistimos a un contexto social que deshumaniza a Berganza, le arrebata todas sus posibilidades de realización (conminándolo siempre a vivir al servicio de alguien más) e incluso el lenguaje. Su encierro representa la economización de la vida y de la muerte (la eficacia del sacrificio). En Hamelin la disposición urbana permite que sean los niños de una colonia pobre quienes se encuentren amenazados por una red de pederastia. La muralla que divide Varsovia (en El Cartógrafo) es una manifestación de la separación y el confinamiento de los hombres en ambos lados de la frontera. El objeto violenta no sólo a quienes está excluyendo, sino que también lo hace con quienes separan, pues, en el fondo, los deja solos. El espacio deviene independiente.

La violencia aparece porque tanto espacio como objeto son políticos, es decir, son confrontados por intenciones alternativas. Por ejemplo, la muralla de Varsovia no representa un conflicto hasta que no haya quien quiera cruzarla.

23 También en esta obra, el mapa es usado para encarnar los problemas y conflictos pasados de un territorio, llevando al futuro espectador directamente hacia los cuerpos y la materialidad que cuentan esta y otras historias. En este sentido, el mapa se materializa como oposición al terror de la ocupación. 
Espacios y objetos estarán en conflicto permanente con los personajes porque (parafraseando a Foucault), los lugares/objetos están irreparablemente ahí, nunca en otro lugar, y los cuerpos «son lo contrario de una utopía, porque nunca están bajo otro cielo» ${ }^{24}$ (Foucault 1966). El conflicto aparece porque el cuerpo del personaje está siempre en un lugar que no desea (Palabra de perro, Himmelweg, El gordo y el flaco) ligado a otros lugares (o quizás a ninguno), surgiendo así una necesidad de atravesar los espacios donde están confinados o de abandonarlos y así poder efectuarse. Espacio y cuerpo(s) se encuentran atravesados por el conflicto.

La legislación misma (como objeto inmaterial regulatorio, pero espacio político), al marcar la (im)posibilidad de ocupación de un territorio o de moverse libremente por él, pone de manifiesto que ha sido concebida desde la violencia. La pieza Animales nocturnos es una muestra de este fenómeno. Este tipo de violencia, según Lambert, es pre-política (no cronológica sino metodológicamente) porque podemos ver que se construye para resistir la energía o voluntad del cuerpo (al igual que cierta arquitectura, como puertas y llaves, permiten establecer quién atraviesa un espacio y quién no). El hecho político está en quien instrumenta un espacio (u otorga ese poder).

Un último aspecto: la violencia siempre varía en grados, nunca en esencia. No es que todo conflicto que aparece en la obra sea político y violento; si así lo denominásemos, correríamos el riesgo de que ambos escenarios perdieran su significado ${ }^{25} \mathrm{o}$ de caer en la postura esencialista que buscamos evitar: la presencia de un elemento de un cuerpo armado no es la misma en un escenario en guerra (Himmelweg) que en un escenario sin guerra ( La paz perpetua), la intensidad política desarrollada es diferente en función del escenario y de la propensión al conflicto, y, por tanto, la violencia varía por igual. Como menciona Lambèrt, todos los cuerpos, animados o inanimados, necesariamente ocupan un espacio y su intensidad y conflicto variarán en función de éste.

Nos queda la impresión de que la posibilidad de emancipación en los espacios mayorguianos es limitada, al menos no de una manera «democrática». Sin embargo, hay que aclarar que esta afirmación es parcialmente cierta, pues si bien la organización de los cuerpos en el espacio (esto es, la arquitectura o el diseño de los espacios) controla la forma en la que espacio y habitantes operan, los personajes pueden encontrar/crear nuevas formas de subversión en este escenario (tal es el caso de la Mujer Alta en Animales Nocturnos, Bulgákova en Cartas de Amor a Stalin o el Flaco en El Gordo y el Flaco, por citar algunos ejemplos).

24 Nuestra traducción.

25 En el mismo sentido, decir que todo es político no significa que todas las cosas sean igualmente políticas pues varía en intensidad dependiendo de su locación. 


\section{Comentarios finales}

Hemos hecho un recorrido histórico superficial a fin de mostrar que la subjetividad de un individuo es indisociable del espacio, en tanto que a través de la interacción co-crea y resignifica la experiencia. Los espacios habitados han sido siempre necesarios para la vida humana, al grado de que su destrucción atenta contra la vida misma (Weizman 2015). El individuo define su entorno sobre/desde el espacio, dota de sentido al lugar y al nombrarlo imprime una naturaleza más rica y compleja (Beltrán 2013: 144). En el mismo sentido, el espacio es estructurado y estructurante, es producto y productor de los bienes básicos para la subsistencia humana y también de la acumulación de riqueza.

Hemos tratado de mostrar que en la obra de Mayorga la violencia opera alterando la cotidianeidad y necesidades de un individuo o comunidad, quizás no alterándole físicamente, sino "civilizándole» por la fuerza. Piezas como Himmelweg y El Cartógrafo ilustran cómo un conflicto (el genocidio) opera, obviamente, en varias escalas, con la intención de destruir varias partes de un grupo. Junto a la guerra aparece un reordenamiento espacial, un cambio en los patrones de urbanización que modifique la vida como solía existir, y eventualmente le extinga.

Al pensar la violencia desde la perspectiva espacial, o, al menos, vinculada a las zonas urbanas, podemos explicar que ésta sea herramienta que refuerce y dirija relaciones de poder, legitime ciertos argumentos y confronte ciertas narrativas (principalmente las heterodoxas). Los espacios construyen verdades, establecen los límites espacio-discursivos del teatro mayorguiano y definen lo que es posible de lo que no.

A fin de concluir, dos aspectos hay que remarcar sobre la obra de Mayorga:

- El espacio topográfico/virtual (ahí donde aparece) y la política se fusionan permitiendo una proyección de la violencia en diferentes intensidades según el contexto. Es decir, es imposible disociar representación política y orden espacial, pues constituyen una sola estructura social interactiva, ambos mantienen la estructura social para la reproducción de la violencia. La fusión de lo histórico (suceso y tiempo) y lo espacial permiten que el espacio sea políticamente autónomo... devenga actor.

- Está atravesada por la relación entre violencia, espacio y memoria, aunque opera en planos diferentes. Las múltiples estrategias de dominación y violencia pueden ser vistas en un plano secundario, detrás de la memoria, la resistencia y la transformación. 


\section{Bibliografía}

Álvarez J., 2013, «El contrato: del individualismo liberal a la masificación de las relaciones económicas», Justicia Juris, 9/1, p. 56-69.

Arrieche A., 2012, «Violencia política y representación: teatro x la identidad 20012011», http://cuadrivio.net/academia/violencia-politica-y-representacionteatro-x-la-identidad-2001-2011/ [Consulta: 17/07/2015].

Augé M., 2000, Los «No lugares» espacios del anonimato. Una antropología de la sobremodernidad, Barcelona, Gedisa Editorial.

Bauman Z., 2009, Confianza y temor en la ciudad. Vivir con extranjeros, Barcelona, Arcadia.

Beltrán S. A., 2013, «Espacios y capitalismo: la crisis capitalista, el territorio y las resistencias sociales. Ciencia Política», 16, p. 138-167.

Benjamin W., 1998, Para una crítica de la violencia y otros ensayos, Madrid, Taurus.

Blair E., 2005, «La violencia frente a los nuevos lugares y/o los "otros" de la cultura», Nueva Antropología, XX(65), p. 13-28.

Blanco A., 2001, «Los cimientos de la violencia», Mente y Cerebro, 49, p. 9-15.

Castells M., 1995, La ciudad informacional. Tecnologías de la información, estructuración económica y el proceso urbano-regional, Madrid, Alianza Editorial.

Cruciani F., 1994, Arquitectura teatral, México/USA, Fideicomiso para la cultura.

Davis M., 2004, «Planeta de Ciudades-Miseria. Involución urbana y proletariado informal», New Left Review, 26, p. 5-34.

De Certeau M., 1984, The Practice of Everyday Life, Berkeley, University of California Press.

Debord G., 2009, Theory of the Derive. The Situationists and the City, Londres, Verso.

Dubatti J., 2007, «Cuerpo social y cuerpo poético en la escena argentina», Revista E-misférica, 4.2., Body matters/corpografrías, http://hemisphericinstitute. org/journal/4.2/esp/es42_pg_dubatti.html [Consulta: 10/08/2015].

Dumouchel P., 2012, «Political violence and democracy», Ristumeikan Studies in Language and Culture, 23(4), p. 117-123.

El País (13/10/2015), «Distribución de la riqueza mundial», http://elpais.com/ elpais/2015/10/13/media/1444754300_420807.html [Consulta: 21/12/2016].

Foucault M., 1966, «Le corps utopique» [conférence radiophonique prononcée le 7 décembre 1966 sur France-Culture], http://culturevisuelle.org/blog/5437 [Consulta: 22/07/2015].

Foucault M., 1979, Discipline and Punish: The Birth of the Prison, New York, Vintage Books.

Galtung J., 1995, Investigaciones teóricas: Sociedad y cultura contemporáneas, Madrid, Tecnos. 
Hardoon D., 2015, «Weatlh: Having it all and wanting more», Research Report. OXFAM International, http://policy-practice.oxfam.org.uk/publications/ wealth-having-it-all-and-wanting-more-338125 [Consulta: 10/07/2015]

Harvey D., 2004, «El nuevo imperialismo: acumulación por desposesión», Socialist Register. El Nuevo desafío imperial, p. 99-129.

Harvey D., 2007, Espacios del capital. Hacia una geografía crítica, Madrid, Akal.

Henri L., 1996, Writings on Cities, Londres, Blackwell Publishers.

Iborra J.V. y Tosarelli L., 2014, Urban Space and violence, Utrecht University [Working paper].

Lambert L., 2015, «Topie Impitoyable. Entrevista con Columbia University GSAPP

(C-O-L-O-N)», The Political, III(1), http://www.c-o-l-o-n.com [Consulta: 23/07/2015].

Latour B., 2004, Politics of nature. How to bring sciences into democracy, Harvard University Press.

Lefebvre H., 2013, La producción del espacio, Madrid, Capitán Swing.

Levy-Daniel H., 2009, «Teatro. Sentido y política», La revista del CCC, 7, http:// www.centrocultural.coop/revista/articulo/138/teatro_sentido_y_politica. html [Consulta: 11/08/2015].

Marcuse H., 1999, Razón y revolución, Madrid, Alianza.

Martín J., 2006, «Pensar juntos espacio y tiempo», in: D. Herrera Gómez y C.E. Piazzini Suárez (eds.), (Des)territorialidades y (no) lugares, Medellín, La Carreta.

Marx K., 1978, El Capital, I, México, F.C.E.

Mayorga J., 2011, Himmelweg, Manuel Aznar Soler (ed.), Ciudad Real, Naque.

Mouffe C., 2007, "Artistic Activism and Agonistic Spaces», Art and Research: A Journal of Ideas, Contexts, and Methods, 1/2, http://www.artandresearch.org. uk/v1n2/mouffe.html [Consulta: 23/07/2015].

Napoli B., 2014, «Luciano Arruga, la batalla del cuerpo», Lobo Suelto, http:// anarquiacoronada.blogspot.fr [Consulta: 30/10/2014].

Núñez Ladevéza L., 1978, "Masificación y democracia en el modelo de masas», Revista de estudios políticos, 5, p. 25-50.

OAS y PNUD, 2010, Nuestra Democracia, México, FCE.

Pallasmaa J., 2006, Los ojos de la piel. Arquitectura y los sentidos, Barcelona, Gustavo Gili.

Pereyra Tissera G., 2011, «Deconstrucción y biopolítica. El problema de la ley y de la violencia en Derrida y Agamben", Revista Mexicana de Ciencias Políticas y Sociología, 56, 212, p. 31-54.

Raz J., 1985, La autoridad del derecho. Ensayos sobre derechos y moral, Imprenta Universitaria, UNAM.

Ritzer G., 1996., La McDonalización de la sociedad. Un análisis de la racionalización en la vida cotidiana, Barcelona, Ariel. 
Rivera Ramos E., 2003, «Derecho y violencia: reflexiones bajo el influjo de una violencia extrema», Yale Law School. SELA Papers, 28.

Sermeño Á., 2000., "Ciudadanía, derechos multiculturales y democracia liberal», Realidad. Revista de ciencias sociales y humanidades, 75, p. 293-304.

Serratore C., 2010., «La violencia y la vida. Biopolítica y Filosofía», http:// biopoliticayfilosofia.blogspot.fr [Consulta: 02/09/2014].

Shaviro S., 18/08/2011, Processes and powers. The Pinocchio Theory, http://www. shaviro.com/Blog/?p=995 [Consulta: 23/07/2015].

Stathis K., 2003, «The Ontology of "Political Violence": Action and Identity in Civil Wars», American Political Science Association, 1(3), p. 475-494.

Tilly C, 2003, The politics of collective violence, Cambridge, Columbia University.

Tschumi R., 2015, «Around the mountain or through the mountain. Entrevista con Columbia University GSAPP (C-O-L-O-N)», The Political, III(1), http:// www.c-o-1-o-n.com [Consulta: 23/07/2015].

Urrutia J., 2004, «Conceptos para una teoría del espectáculo», in: Pelletieri Osvaldo (ed.), Reflexiones sobre el teatro, Galerna, Buenos Aires.

Weizman E., 2015, «First degree murder by architecture», http://www.c-o-lo-n.com/3_1eyal.html [Consulta: 30/09/2015].

Wood J.C., 2007, «Locating violence: the spatial production and construction of physical aggression», in: Watsonx Katherine D. (ed.), Assaulting the Past: Violence and Civilization in Historical Context, Newcastle, Cambridge Scholars Publishing, p. 20-37.

Žižek S., 2008, Violence, Nueva York, Picador. 